\title{
The Cultivation of Critical Thinking Ability in Academic Reading Based on Questionnaires and Interviews
}

\author{
https://doi.org/10.3991/ijet.v15i22.18197 \\ Jian Li ${ }^{(凶)}$, Yan Ren \\ Xi'an University of Technology, Xi'an, China \\ ccyxz@xaut.edu.cn
}

\begin{abstract}
In recent years, Chinese college students have been criticized for having nothing to say, no thinking ability, and lack of critical thinking. Cultivating students' thinking ability is becoming an important task of higher education. Through carrying out questionnaire survey and interviews, the author learned that graduate students' critical thinking skills in academic reading needs to be improved. To improve the situation, it requires joint efforts of teachers and students to improve students' critical thinking ability in academic reading, which is conducive to the completion of academic papers and the improvement of students' thinking ability, so as to meet the requirements of higher thinking ability for students in the 21 st century.
\end{abstract}

Keywords - Critical thinking ability, academic reading, interview

\section{$1 \quad$ Introduction}

Critical thinking ability is defined as "the ability to make purposeful and rational judgments on things or opinions according to standards" [1]. It is composed of critical thinking disposition and critical thinking skills. The critical thinking disposition refers to the consistent habitual thinking motivation of individuals when solving problems, conducting analysis and making decisions. The positive critical thinking disposition benefits human progress and social development, while the negative critical thinking disposition tends to harm the society. Critical thinking skills refer to the application of appropriate evaluation standards to consciously think and finally makes rational judgment [2]. This paper mainly studies critical thinking skills. Scholars once put forward the absence of critical thinking, and mentioned that English majors lacked certain critical thinking ability. Since then, more and more scholars have paid attention to this problem and conducted researches and discussions in various aspects. Many scholars discussed the development of measuring tool for critical thinking ability, such as Wen Qi fang and Wang Jianqing [3-4]. A series of comparative studies by Wen Qi fang were conducted on the critical thinking ability between college students majoring in foreign languages and other college students majoring in art and science [5-6]. Some scholars studied the reasons for the lack of critical thinking ability of current college students and the training program, and involved the cultivating the critical thinking ability of foreign language teachers in colleges and universities [7-8]. 
Therefore, we can know the current situation of foreign language students and teachers in the cultivation of critical thinking ability in colleges and universities, that is, foreign language students' critical thinking ability is no less than that of students of other majors, and the overall thinking disposition of foreign language students is positive. The teacher is short of critical thinking ability, which restricts the cultivation of students' critical thinking ability to some extent. At the same time, scholars also combined critical thinking skills with foreign language listening, speaking, reading, writing and other aspects to carry on research, and the majority is about listening and writing [9]. There are few studies that combine academic reading with the cultivation of critical thinking ability. This is only in the study of foreign languages, and the lack of critical thinking ability is common in university graduate students.

Tilaka introduced "academic reading" or "reading for academic purposes" (RAP) earlier. She pointed out that the academic reading course is an advanced reading course, opening to students who have completed the primary intensive reading course, or as a preparatory course (the course is offered to students who will study ESP courses) [10]. In the process of postgraduate training, it is essential to write a paper, which requires reading a large amount of literature, putting forward one's own opinions on the basis of previous studies, and promoting the development of related fields. At the same time, reading literature is also an important way to acquire relevant professional knowledge and theories. In the previous study, many scholars adopt the method of measurement to study the related problems such as students or the teacher's critical thinking ability [11-13]. However, because foreign language research cannot be operated in a vacuum laboratory, and the variables cannot be well controlled, the research results may have a certain deviation. It is necessary for us to study the critical thinking ability of foreign language students in literature reading and how to improve the status quo through qualitative methods, so that it can better serve academic reading. The academic reading of this study refers to the reading accumulation in specific fields conducted by graduate students majoring in foreign language in order to complete term papers or graduation papers within a fixed period of time. Therefore, it does not include the academic reading carried out by some people due to their hobbies. Students need to write papers that meet certain standards within a limited time, more attention should be paid to the method in the process of reading. Only with correct thinking guidance can we achieve twice the result with half the effort. Foreign language majors are required to read and write literature during their postgraduate study, which is also a key period to cultivate their critical thinking ability. The learning abilities and ways of thinking cultivated in this process are of great significance to the students' academic research or work in the future [14-15]. Based on the previous study, this paper knows the current situation of the critical thinking ability of foreign language majors in literature reading through questionnaire survey and interview, and tries to put forward some feasible suggestions based on the specific research results. 


\section{$2 \quad$ Research Process and Results}

\subsection{Questionnaire design}

In 2009, Wen Qi fang proposed a hierarchical model of critical thinking based on the dual-dimensional structural critical thinking model proposed by the Delphi project team, Richard Paul's ternary structural critical thinking model and Lin chongde's Mitsubishi structural thinking model According to the hierarchical model, critical thinking ability includes two levels, namely meta-critical thinking ability and critical thinking ability. Meta-critical ability refers to the critical thinking disposition mentioned above, which means the ability to judge and adjust one's critical behavior in a timely manner. The second level is the critical thinking ability to be further studied in this paper, including skills and standards related to cognition, as well as emotional traits related to critical quality. Among them, cognitive skills include analysis, reasoning, and evaluation, and cognitive criteria include clarity, relevance, logic, profundity, and flexibility. Emotional traits include curiosity, openness, confidence, integrity, and fortitude [11]. This paper sets up a questionnaire survey based on the 13 dimensions in hierarchy model, a total of 24 questions. The Likert scale is adopted, and the scale is composed of declarative sentences. Each statement has six answers of "strongly agree", "quite agree with", "relatively agree", "accept", "quite disagree", "strongly disagree". The answers were recorded as 1, 2, 3, 4, 5, and 6 respectively, and 30 postgraduates majoring in foreign languages were randomly selected for testing. Finally, 29 valid questionnaires were obtained, the purpose of which was to find out whether the current foreign language postgraduates have the critical thinking ability during academic reading. The following is the specific content of the questionnaire.

Dear students,

Hello!

Thank you very much for taking the time to fill in this questionnaire.

The purpose of this questionnaire is to understand the current situation of the critical thinking ability of foreign language postgraduates in academic reading. There are no right or wrong answers in your answers, and the results of the questionnaire are only used for scientific research and will never be disclosed. I hope you don't have any concerns and fill in according to your real situation and ideas to ensure the reliability of the survey. Thank you for your support and cooperation! Thank you very much!

Here are questions you need to answer. Some views you may strongly agree with, others you may disagree with. Please fill it according to your actual condition. Read each sentence carefully and make sure you understand its meaning. Then choose the corresponding number according to the following table to show how much you agree with this opinion under the corresponding question. 
Table 1. Agreement with the questions

\begin{tabular}{|l|c|c|c|c|c|c|}
\hline Degree & Strongly agree & Quite agree with & Relatively agree & Accept & Quite disagree & Strongly disagree \\
\hline Score & 1 & 2 & 3 & 4 & 5 & 6 \\
\hline
\end{tabular}

Please make a true assessment according to your own situation and don't leave anything out.

Analysis

1. The articles can be accurately classified in the literature reading.

$\begin{array}{llllll}1 & 2 & 3 & 4 & 5 & 6\end{array}$

2. You can compare articles on the same research topic and find the subtle differences

$\begin{array}{llllll}1 & 2 & 3 & 4 & 5 & 6\end{array}$

Reasoning

3. When you see something that goes against your existing knowledge, you will dare to question it

$\begin{array}{llllll}1 & 2 & 3 & 4 & 5 & 6\end{array}$

4. The opinion your agreed with can be accurately demonstrated with relevant knowledge

$\begin{array}{llllll}1 & 2 & 3 & 4 & 5 & 6\end{array}$

5. Make some valid judgments on the preset questions or conclusions in the literature

$$
\begin{array}{llllll}
1 & 2 & 3 & 4 & 5 & 6
\end{array}
$$

6. Take an objective look at the conclusions drawn in the literature and know its good points and limitations

$\begin{array}{lrllll}1 & 2 & 3 & 4 & 5 & 6\end{array}$

7. Be clear and accurate when analyzing problems

$\begin{array}{llllll}1 & 2 & 3 & 4 & 5 & 6\end{array}$

8. When analyzing the literature, it is possible to have clear priorities and know the core contents of the literature

$\begin{array}{lrllll}1 & 2 & 3 & 4 & 5 & 6\end{array}$


9. You are kind of a logical person

$$
\begin{array}{llllll}
1 & 2 & 3 & 4 & 5 & 6
\end{array}
$$

10. When discussing a point of view in the literature, one should not say that it is right or wrong, but analyze it based on certain evidence

$\begin{array}{llllll}1 & 2 & 3 & 4 & 5 & 6\end{array}$

11. When you read the literature, you can think of a wider research scope than the paper itself

$\begin{array}{llllll}1 & 2 & 3 & 4 & 5 & 6\end{array}$

12. When you read literature, you can think of something more profound about the author's point of view

$\begin{array}{llllll}1 & 2 & 3 & 4 & 5 & 6\end{array}$

Flexibility

13. When analyzing problems, you seldom have inertial thinking and can reasonably change the perspective of analyzing problems at any time

$$
\begin{array}{llllll}
1 & 2 & 3 & 4 & 5 & 6 \\
\text { (Emotion) } & \text { Curiosity } & &
\end{array}
$$

14. I am always curious about various viewpoints and research methods in the literature I read and want to know more about them

$$
\begin{array}{llllll}
1 & 2 & 3 & 4 & 5 & 6
\end{array}
$$

15. When I find a problem I don't understand, I will try my best to collect all relevant articles and materials

$$
\begin{array}{llllll}
1 & 2 & 3 & 4 & 5 & 6 \\
\text { Openness } & & & & &
\end{array}
$$

16. It is also important to read foreign literature and learn more about other people's opinions and ways of dealing with things

$$
\begin{array}{llllll}
1 & 2 & 3 & 4 & 5 & 6
\end{array}
$$

17. For the same research content, I will not pay attention to the different conclusion but the one I think is correct

$\begin{array}{llllll}1 & 2 & 3 & 4 & 5 & 6\end{array}$

18. When I have an open mind, I don't know what is true and what is false

$\begin{array}{llllll}1 & 2 & 3 & 4 & 5 & 6\end{array}$




\section{Self-Confidence}

19. Even when reading articles in authoritative journals, I still question the irrationality of the author's opinion

$\begin{array}{llllll}1 & 2 & 3 & 4 & 5 & 6\end{array}$

20. I have no doubt about what I believe

$\begin{array}{llllll}1 & 2 & 3 & 4 & 5 & 6\end{array}$

21. The truth is nothing more than a person's opinion

$\begin{array}{llllll}1 & 2 & 3 & 4 & 5 & 6\end{array}$

22. In order to get a thorough understanding of a point, I will read a lot of relevant papers and materials

$\begin{array}{llllll}1 & 2 & 3 & 4 & 5 & 6\end{array}$

Fortitude

23. In the process of reading, I will ignore the content that are difficult to understand

$\begin{array}{llllll}1 & 2 & 3 & 4 & 5 & 6\end{array}$

24. I am willing to learn and read in order to acquire knowledge

$\begin{array}{llllll}1 & 2 & 3 & 4 & 5 & 6\end{array}$

The test is now over. Thank you for your cooperation!

\subsection{Questionnaire results and analysis}

It can be seen from the questionnaire results that about half of the students can objectively analyze and reason about the literature when they read the literature in terms of the cognitive skills (analysis, reasoning and evaluation), and one third of them can hardly classify the literature and compare the literature on the same topic. In terms of cognitive standard (clarity, relevance, logicality, profundity and flexibility), in addition to the depth and flexibility, everyone's ability is similar to the above cognitive standard. From the perspective of depth, only $38 \%$ of the students can be sure that they can think of a broader and deeper level than that of the article when reading, and $34 \%$ of the students can hold less inertial thinking when solving problems and can reasonably change the perspective of the analysis. Therefore, it is found that the students lack profundity and flexibility under the cognitive standard of critical thinking ability. In terms of the emotional traits, it can be seen that from the data that in the process of reading, most students would like to understand some new ideas or confused views in the literature, but at the fortitude level, one of the problem is "in the process of reading, I will ignore the content that are difficult to understand", and 55\% of students chose strongly agree, reflecting that students will ignore the part that needs 
to study and think when reading, which will also affect the cultivation of critical thinking ability and the improvement of literature reading level. Thus, according to hierarchy model of critical thinking ability put forward by Wen Qi fang in 2009 and the questionnaire survey result, it can be seen that the current students in the process of literature reading, most of the students can analyze and categorize the literature, and will boldly question some of the different views, and can also use their existing knowledge to demonstrate related views, etc. They can also demonstrate relevant viewpoints with their own existing knowledge. There is a certain critical thinking ability and it will also be applied into literature reading. But there are also some problems, mainly manifested in the profundity and flexibility under the cognitive standard of critical thinking ability, and the fortitude in the emotional characteristics, which requires corresponding measures to improve the status quo. We must also continue to improve students' critical thinking ability in reading literature as a whole.

Table 2. Questionnaire results

\begin{tabular}{|l|c|c|c|}
\hline $\begin{array}{c}\text { The questionnaire } \\
\text { items }\end{array}$ & $\begin{array}{c}\text { The percentage of people } \\
\text { who "strongly agree", "quite } \\
\text { agree with", "relatively } \\
\text { agree" }\end{array}$ & $\begin{array}{c}\text { The percentage of } \\
\text { people who "accept" }\end{array}$ & $\begin{array}{c}\text { The percentage of people } \\
\text { who "quite disagree", } \\
\text { "strongly disagree" }\end{array}$ \\
\hline Analysis & $55 \%$ & $37.5 \%$ & $7.5 \%$ \\
\hline Reasoning & $46.5 \%$ & $46.5 \%$ & $7 \%$ \\
\hline Evaluation & $60 \%$ & $37 \%$ & $3 \%$ \\
\hline Clarity & $62 \%$ & $31 \%$ & $7 \%$ \\
\hline Relevance & $72 \%$ & $24 \%$ & $4 \%$ \\
\hline Logicality & $67 \%$ & $24 \%$ & $8 \%$ \\
\hline Depth & $38 \%$ & $36 \%$ & $18 \%$ \\
\hline flexibility & $34 \%$ & $48 \%$ & $13 \%$ \\
\hline curiosity & $65 \%$ & $22 \%$ & $43 \%$ \\
\hline Openness & $43 \%$ & $14 \%$ & $21 \%$ \\
\hline Confidence & $41 \%$ & $38 \%$ & $33 \%$ \\
\hline Integrity & $55 \%$ & $12 \%$ & $27 \%$ \\
\hline Fortitude & $41 \%$ & $22 \%$ & \\
\hline
\end{tabular}

\subsection{Interview design}

Interview method is a supplement to the questionnaire survey. After the questionnaire survey, the interview method is used to further research the status quo of the current graduate student's critical thinking ability in literature reading. The interview is a research communication activity, which constructs the theoretical significance of the research question through the researcher's active inquiry and the interviewee's deep expression [12]. Interview objects basically are the part of the college postgraduate student, and it is willing to do comprehensive and objective investigation as far as possible. The students include study of masters and professional master degree. due to the limited conditions, only eight people were interviewed, involving master of interpreting and translation, foreign languages and applied linguistics, resource utilization and plant protection, Qin and Han dynasties archaeology, pharmaceutical 
chemistry, transportation engineering, and they are close in age. They did not receive systematic academic reading training during their university or postgraduate study, but had the experience of reading literature and writing papers before that. The longest paper they wrote was the undergraduate graduation thesis, and they did not pay attention to their critical thinking ability. The main purpose of the interview is to further know the real situation of the postgraduates' critical thinking ability in academic reading based on the questionnaire survey results above, with the purpose of interviewing the most real feelings and situations. Try to ensure that the interviewee speaks freely in a relaxed environment and expresses his or her truest thoughts. Here are some questions involved. First, what do you think of the overall critical thinking ability of the students in your college? Second, do you read a lot of literature? What is the feeling after reading, did you encounter any problems? Third, can critical thinking be achieved when reading literature? Four, do you think your substitute teacher is good at critical thinking? Fifth, are there any suggestions to improve critical thinking ability in academic reading?

\subsection{Analysis and discussion of interview results}

The grounded theory was used to analyze the interview data. The grounded theory is a construction method widely used in qualitative research. It is a theoretical construction method from bottom to top, and researchers need to analyze and conclude conclusions from the initial data collection and analysis to form a theory.

First level coding: Since the first student and the author is not in the same city, the telephone interview was conducted by chat. After that, in the process of sorting, the missing content was questioned again. The interview process was as relaxed as possible. Therefore, there are many contents that are not related to this paper and they have been deleted.

\section{After encoding the interview data of the first classmate, a total of 11 initial codes have been generated, namely:}

1.1 Students around her have strong critical thinking ability, but some of them are pushed around; 1.2 Read less literature, and she will read the literature when encountering problems in the subject 1.3 mainly read the abstract and find the way to solve the problem; 1.4 Do not pick the journal level; 1.5 take notes occasionally, but not most of the time; 1.6 fails to think critically, she can find something unreasonable in the literature; 1.7 I think the author of the paper makes sense in this way 1.8 reading literature is helpful, I can better understand the literature content, which inspire her scientific research experiment; 1.9 at present, there is no critical thinking ability, but I will develop the way of thinking in the future; 1.10 the majority of teachers have no critical thinking ability. 1.11 teachers can inspire students' critical thinking ability in class or in their daily communication with students. Students should pay attention to cultivate their critical thinking ability in their daily life and study.

\section{After encoding the interview data of the second student, 9 initial codes were generated, which were as follows:}


2.1 Everyone has a certain critical thinking ability; 2.2: the main purpose of reading literature is to search for data, or to verify archaeological data, so as to increase the literature base. It feels obscure; 2.3 I find key points without notes, I don't care the journal level; 2.4: it cannot be reached, because it is not easy to grasp due to its large content; 2.5 the literature could have done better; 2.6: it plays an important role. Thinking and discerning are inseparable. Literature reading requires not only thinking ability, but also discerning in thinking. Critical thinking ability is conducive to grasping the key points and finding the key points in literature reading, which is conducive to better read literature; 2.7 : I have been paying attention to it; 2.8 the ability is required in literature reading and other aspects; 2.9: teachers have high thinking and judgment abilities. In the process of communication, they teach and improve our ability in thinking and judgment, so as to prevent us from blindly following the literature.

\section{After encoding the interview data of the third student, 10 initial codes are generated, which are as follows:}

3.1 Students around have good critical thinking ability; 3.2 I rarely take the initiative to read. The teacher emphasized and I just read to write papers, and read literature related to my task; 3.3 be careful and be good at summing up; 3.4 I take notes and write down main points to help me write the paper; 3.5 read more can distinguish the pros and cons of the paper; 3.6 learn to take academic notes and keep academic diaries, which will make me have a sense of achievement and conducive to later writing; 3.7 blindly accept in the early stage; 3.8 reading a lot will lead to critical thoughts; 3.9 the order of reading is very important. The journal level is very important; 3.10 critical thinking ability is essential. In the process of thinking, you can find new fields and realize academic innovation.

\section{After encoding the interview data of the fourth student, 7 initial codes were generated, which were as follows:}

4.1 The students around have good critical thinking ability, and can make a detailed analysis of things and problems; 4.2 I read literature in order to improve the reading ability and expand the thinking; 4.3 I will choose the journal level, there is no fixed method, I choose what I like to read. I take notes about what I don't know; 4.4. I can't. There is something unreasonable. Critical thinking in some literature is too absolute; 4.5. Helpful, we should understand literature more comprehensively and cultivate critical thinking ability; 4.6. Yes, I will be reading a lot of similar papers; 4.7. Yes, the teacher is teaching by words and deeds to influence the students' critical thinking ability.

\section{After encoding the interview data of the fifth student, 11 initial codes were generated, which were as follows:}

5.1 Students' critical thinking ability is good on the whole; 5.2 I read a part of literature, but have no clear direction; 5.3 I will select the papers I need to take intensive reading. Reading core journals and SCI articles recommended by teachers; 5.4 I take notes on abstracts and research methods; 5.5 teachers mention critical thinking and 
repeatedly emphasize and focus on cultivating it; 5.6 it is difficult for me to find the deficiencies of the article due to my existing knowledge; 5.7 I lack of critical thinking, but I try to cultivate it; 5.8 critical thinking is very important for reading literature, because we need to take the essence of the literature to carry out our research. 5.9 I have been trying to cultivate, our teacher is also emphasizing; 5.10 the substitute teacher has critical thinking. He/she will talk about the cutting-edge theories in the field of transportation in class and analyze them so that we can identify them by ourselves. 5.11 teachers pay attention to critical thinking and require students to write innovative papers.

\section{After encoding the interview data of the sixth student, 7 initial data are gener- ated, which are as follows:}

6.1 Yes, but not very good; 6.2 I read literature when doing homework; 6.3 reading literature is mainly for the purpose of finding ideas. Read intensively what needs to be quoted, other parts will not be studied in detail. $6.4 \mathrm{I}$ do not understand some research methods of science, so it is difficult to study by myself; 6.5 reading literature is mainly for learning tasks; 6.6 no, the teacher is blind and has no skills to teach how to learn critical thinking ability; 6.7 the tutor requires students to read more books, then cultivating the ability. Besides, critical thinking ability and literature reading are a twoway process. A book list can be made, and the teacher will lead students to communicate regularly after class.

\section{After encoding the interview data of the seventh student, eight initial codes were generated, which were as follows:}

7.1 Not very good; 7.2 I don't read literature. I will read it with questions unless I have an assignment or a thesis to be finished. 7.3 I take notes to quote without much thinking; 7.4 I cannot think critically; 7.5 in the process of reading, I have been learning all the time. I know little and cannot be critical. 7.6 teachers guide us to think independently, but students avoid it; 7.7 it needs practice combined with academic writing. It is not easy to cultivate due to the lack of critical thinking ability in the whole country. 7.8 a wide range of knowledge is required. Teachers can assign homework and let students think by themselves.

\section{After encoding the interview materials of the eighth student, five initial codes were generated, which were as follows:}

8.1 Not so good; 8.2 when doing projects, I will read literature without any problems. I choose advanced journal to study. 8.3 the view of authority is correct; 8.4 the tutor emphasized that one should have his own ideas and insights, but did not give specific methods. The teacher doesn't realize it; 8.5 The subjective factors of liberal arts students are too strong; research can be conducted combined with some scientific research methods. students should think much.

Second-level coding: This process is based on the collation and induction of the first-level code. The author carefully compares the code with the original text and confirms that there are no errors or omissions or repeated coding, so that the first- 
level code is divided according to a certain standard to form a higher-level and more general second-level code. It is a bottom-up process. The author conducted a detailed study and comparison to try to find the internal connection of the above materials. After repeated reading, it was found that the materials could be roughly divided into five categories, namely, the reasons for reading the literature, the method of reading the literature, the degree of critical thinking in the reading process, teachers' attention on critical thinking, and the suggestions proposed by students on improving critical thinking. With the exception of individual content, the rest of the content can be categorized into these five parts.

\section{The second level code of the first student's interview data}

Reasons for literature reading -- problems encountered in the project

Literature reading method -- read the abstract and take notes

Critical thinking in the process of reading -- don't question too much what they find unreasonable

Teachers' attention on critical thinking -- most teachers do not pay attention to it

Suggestions proposed by students -- teachers communicate more with students on critical thinking, including daily life and study

\section{Second-level coding of the second student's interview data}

Reasons for literature reading -- verification of archaeological data

Literature reading method -- find the key points

Teachers' attention on critical thinking -- teachers have critical thinking ability, and pay attention to cultivating students' critical thinking ability

Suggestions proposed by students -- pay more attention to it and cultivate the critical thinking ability

\section{Second-level coding of the third student's interview data}

Reasons for reading literature -- the teacher require students to write a paper

Literature reading methods -- take academic notes, keep academic diaries, and read more

Critical thinking in the process of reading -- no critical thinking ability at first, and be able to distinguish the pros and cons of the article after reading a lot

Teachers' attention on critical thinking -- teachers try to cultivate students' critical thinking ability

Suggestions proposed by students -- read the papers of leading figures in the academic world

\section{The second level code of the fourth student's interview data}

Reasons for literature reading -- interest

Method of literature reading -- there is no fixed method

Critical thinking in reading -- fail to think critically

Teachers' attention on critical thinking -- teachers have a subtle influence on the students 
Suggestions proposed by students -- read a lot of articles in the related field

\section{The second-level code of the fifth student's interview data}

Reasons for reading literature -- teacher's recommendation

Literature reading methods -- take notes on abstracts and research methods read articles from core journals, and read extensively

Critical thinking in the process of reading -- no critical thinking ability, try to cultivate.

Teachers' attention on critical thinking -- the teacher attaches great importance to it and intends to cultivate it

Suggestions proposed by students -- important for academic research and it need to be cultivated.

\section{Second-level code of the sixth student's interview data}

Reasons for reading literature -- homework, find research ideas

Literature reading methods -- the research methods of science students is required but he cannot understand

Critical thinking in the process of reading -- no critical thinking ability, try to cultivate

Teachers' attention on critical thinking -- the teacher requires students to read more books, but the teacher lacks critical thinking ability.

Suggestions proposed by students -- one should will to study and read more papers.

\section{Second-level code of the seventh student's interview data}

Reasons for reading literature -- homework and papers need to be finished

Literature reading method -- mark the parts that need to be cited

Critical thinking during reading -- no

The teacher's attention on critical thinking -- the teacher will ask questions to guide the students to think

Suggestions proposed by students -- they should have a wide range of knowledge and practice combined with academic writing, and be guided by teachers

\section{The second-level code of the eighth student's interview data}

Reasons for reading literature -- conduct projects

Literature reading method -- select the high-level journal

Critical thinking during reading -- no

The teacher's attention on critical thinking -- most teachers have no critical thinking ability

Suggestions proposed by students -- combine with the research methods of science to do research and think more

Three-level coding: After the completion of the second-level coding, the research was promoted to a new level. Based on the second-level coding, this part further summarizes to generate the final interview results about the current status of the critical thinking ability of the current postgraduate students in the academic reading: the 
current status of the critical thinking ability of the postgraduate in literature reading and the measures to improve the critical thinking ability.

Table 3. Analysis of the interview results

\begin{tabular}{|l|l|}
\hline $\begin{array}{l}\text { The status quo of critical } \\
\text { thinking ability of postgradu- } \\
\text { ate in literature reading }\end{array}$ & $\begin{array}{l}\text { Not optimistic, most students have difficulty in thinking critically when } \\
\text { reading literature }\end{array}$ \\
\hline $\begin{array}{l}\text { Measures to improve the } \\
\text { critical thinking ability }\end{array}$ & $\begin{array}{l}\text { Teacher: Improve their own thinking ability, and guide students to cultivate } \\
\text { their thinking ability. } \\
\text { Students: Increase the amount of reading, think much. Combine comprehen- } \\
\text { sive research methods in the liberal arts and sciences for learning and re- } \\
\text { search. }\end{array}$ \\
\hline
\end{tabular}

From the interview results, the current status of the critical thinking ability of the postgraduate in literature reading in our country is not very optimistic, including liberal arts and sciences. Firstly, most students do academic reading for the purpose of completing semester assignments or small papers. It is utilitarian reading without indepth study of knowledge, so their critical thinking ability is poor. Secondly, the low amount of reading and the lack of professional knowledge result in the students' learning mentality in the process of reading literature, and they are unable to judge the accuracy of knowledge, affecting the reading efficiency and quality. Thirdly, some students or Chinese students have received the Chinese inculcated education mode for a long time, and they mechanically accept it and have a rigid learning style, regardless of the reason for knowledge acquisition, which is extremely unfavorable to the cultivation of students' critical thinking ability. Fourthly, we can see from the interview that the critical thinking ability of foreign language teachers also needs to be greatly improved. At present, the critical thinking ability of foreign language teachers in colleges and universities in China is not optimistic, and the heads of foreign language departments agree with the objective situation that foreign language teachers are not strong or lack of critical thinking ability [4]. Therefore, the critical thinking ability of teachers, the main force of cultivating students, is not optimistic and it is difficult to cultivate students' critical thinking ability.

\section{Discussion of Questionnaire Survey and Interview Results}

Based on the results of questionnaire and interview, at present, postgraduate students are generally lack of critical thinking ability when reading literature. Only a few students can think critically while reading, avoid inertial thinking. In addition, the profundity and flexibility of students under the cognitive standards of critical thinking ability, as well as the perseverance in emotional traits, especially need to be further cultivated. Furthermore, the status quo of our foreign language teachers' critical thinking ability is not optimistic and needs to be improved. 


\section{Measures to Cultivate Critical Thinking Ability}

Chinese students have long been criticized for their lack of ideas and critical thinking. Through questionnaires and interviews, we can also find that students lack critical thinking ability in academic reading. Through this study, the author learned some real situations and put forward some suggestions to try to improve the current situation. Specific measures can be taken from both teachers and students according to the above research results, and then measures should be taken to solve the problems of students under cognitive standards and emotional traits.

\subsection{Teachers}

Improve the critical thinking ability of teachers. According to the interview, in most cases, the teacher fails to provide timely and appropriate guidance and education for the cultivation of students' critical thinking ability in the process of learning. Because teachers also lack critical thinking ability, we need to focus on the core of cultivating critical thinking ability -- teachers. Encourage foreign language teachers to read more books that cultivate their critical thinking ability and form a complete systemic thinking. "A creative teacher must have an educational view, knowledge structure, personality and others conducive to the development of students' creativity to lead students to question and ask meaningful questions. Teachers should not presume write or wrong things with authority and not evaluate the results in the process. Practice shows that teachers' innovative teaching methods can not only promote the development of students' critical thinking ability, but also facilitate the development of students' mental skills and personality by enhancing students' ability to acquire knowledge and apply knowledge actively and to examine problems logically. Critical thinking must be inseparable from innovation. Therefore, creative teachers are needed to improve students' critical thinking ability in academic reading, which is also one of the ways to solve the current crisis of foreign language majors.

\subsection{Students}

Critical thinking ability is the ability of a person to recognize things and understand them [15]. In particular, critical thinking is required in literature reading. Only by dialectically looking at the views of predecessors and the ways to solve problems can one find his own interests and research fields, which is also conducive to academic writing. Firstly, reading is the foundation, and positive critical thinking requires a deep understanding of the field. The scope can be defined by the teacher, or the students can choose reading material according to their interests, and read the articles of experts, including books, excellent papers by experts and works of foreign language majors to accumulate the amount of reading and books can be read extensively to deepen your understanding of the research area, avoiding random doubts or objections to subject knowledge. Secondly, read critically. Students should not be superstitious about authority. Even papers published in authoritative journals or papers by well- 
known scholars may have deficiencies. We can think about whether we can raise new important questions based on this paper or consider whether there is a better research path for the same problem, which is conducive to the cultivation of critical thinking ability and the improvement of reading level and efficiency. Thirdly, in the interview, students also mentioned that academic reading should be combined with academic writing, and practice is more conducive to the in-depth reading and the cultivation of critical thinking ability. Academic reading and academic writing also promote each other. Fourthly, the author holds that students in academic reading should take reading notes, the note taking is not just a passive copy but trying to figure out the author's intention and communicate with the author. Long-term study in this field can accumulate professional knowledge and understand the field more systematically and logically. Essay writing training is of great significance to academic reading. On the other hand, through long-term dialogues with experts, the reader's own thoughts will be more profound and comprehensive. With the increase of knowledge and deep thinking, students will cultivate objective reading habits instead of blindly browsing. Students should also cultivate their own studious and inquisitive learning habits, as well as the spirit to bear hardships and stand hard work in learning. In the process of literature reading, students should not be afraid of problems and new ideas, and try to solve them by consulting materials in person as much as possible, so as to make great progress in learning.

\section{Conclusion}

To sum up, improving students' critical thinking ability in academic reading requires the joint efforts of teachers and students. Students' critical thinking ability is the result of multiple disciplines. Through questionnaire and interview, this paper found that there are many problems of students' critical thinking ability in academic reading, such as utility reading, low reading amount and unable to understand the core content of professional fields, as well as the long-term indoctrinated education, the formation of inert thinking, and in the profundity and flexibility under cognitive standards and emotional traits of critical thinking ability, as well as the perseverance still need to be further improved. The lack of teachers' critical thinking ability lead to student's lack of critical thinking ability in academic reading. the author thinks that can take some measures to improve this situation. It may take a long time, but it certainly pays off. Furthermore, the spirit of the pursuit of truth. The yearning and love for academics are the "mental mentors" for postgraduate students to enter the academic hall. Encourage students to pursue spiritual and academic progress, and promote non-utilitarian reading and learning. In this way, the learning effect will be doubled with half the effort.

\section{References}

[1] Wahyudi, Verawati, N.N.S.P., Ayub, S., Prayogi, S. (2019). The effect of scientific creativity in inquiry learning to promote critical thinking ability of prospective teachers, Inter- 
national Journal of Emerging Technologies in Learning, 14(14), 122-131. https://doi.org/10.3991/ijet.v14i14.9532

[2] Elder, L., Paul, R. (2020). Critical thinking: Tools for taking charge of your learning and your life. Pearson Prentice Hall.

[3] Wen, Q.F., Wang, J.Q. (2011). Study of the reliability of critical thinking disposition inventory for Chinese colleges students. Educational Technology for Foreign Language Teaching, 11(142): 19-21.

[4] Wang, J.Q., Wen, Q.F. (2011). Introduction of critical thinking instruments from abroad and some inspirations. Journals of Jiangsu Teachers University of Technology, 17(7): 3942.

[5] Wen, Q.F., Wang, H.M., Zhao, C.R. (2010). A comparative study of the thinking ability of Chinese English majors and other liberal arts college students. Foreign Language Teaching and Research, 42(5): 350-354.

[6] Wen, Q.F., Zhang, L.L. (2014). Are foreign language major's inferior to the other majors in critical thinking. Modern Foreign Language, 37(6): 794-802.

[7] Sun, Y.Z. (2015). Foreign language education and cultivation of thinking ability. Foreign Languages in China, 12(2): 21-23.

[8] Abdi, A.S., Cavus, N. (2019). Developing an electronic device to teach English as a foreign language: Educational toy for pre-kindergarten children, International Journal of Emerging Technologies in Learning, 14(22), 29-44. https://doi.org/10.3991/ ijet.v14i22.11747

[9] Wang, Y. (2018). A new model of foreign language listening with the goal of language ability, critical thinking ability and cross-cultural ability. Foreign Language Education, 39(6): 69-72.

[10] Tilaka, A., Zhang, Y.G. (1987). The teaching approach of academic reading. Foreign Language Teaching Abroad, (2): 21-26.

[11] Wen, Q.F., Wang, J.Q., Zhao, C.R. (2009). Constructing a theoretical framework for measuring the speculative ability of college students in foreign languages. Foreign Language World, 130(1): 42-46.

[12] Dang, D.F., Wang, J.Y. (2002). Analysis on the interview method in educational research. Educational Review, (2): 31-38.

[13] Yang, Q. (2018). Research on the promotion of teaching academic ability of local university teachers- a qualitative research based on S University. Shanxi University.

[14] Sun, Y.Z. (2011). Emphasize the cultivation of thinking ability, and deepen the teaching reform of English majors. Foreign Language in China, 8(3): 54-58.

[15] Zhu, Y., Kong, L.Q. (2016). Qualitative study on reading competence of foreign postgraduates majoring in Chinese. TCSOL Studies, 65(1): 31-35.

\section{$7 \quad$ Authors}

Jian $\mathbf{L i}$ is a faculty of Humanities and Foreign Language and an associate professor of School of Humanity and Foreign Language in Xi'an University of Technology. She received her M.A. in Foreign Linguistics from University for Science and Technology in 2007. Her research interested fields include cognitive linguistics, rhetoric 
writing. she has teaching experience of 13 years, has completed six scientific research projects and has published 2 books and more than 15 papers in various journals. Email: ccyxz@xaut.edu.cn

Yan Ren is a master degree candidate of School of Humanity and Foreign Language in Xi'an University of Technology. She received her B.A. in English Language and Literature from Shanxi University in 2017. Her research interested fields include cognitive linguistics, translation and second language acquisition. E-mail: 1371935560@qq.com

Article submitted 2020-09-02. Resubmitted 2020-10-12. Final acceptance 2020-10-14. Final version published as submitted by the authors. 